\title{
LITERATUR REVIEW: PENGARUH PEMBERIAN ASI PADA IBU POSTPARTUM DENGAN KEJADIAN POSTPARTUM DEPRESSION
}

\author{
Hanifatur Rosyidah', Ainaya Hafizatul Adibiyah ${ }^{2}$ \\ Universitas Islam Sultan Agung Semarang ${ }^{12}$ \\ e-mail: ainaya.hafiza799@gmail.com ${ }^{2}$
}

\begin{abstract}
Postpartum depression is the situation of depression experienced by mothers after giving birth. Postpartum depression affects the reduction or cessation of the process of breastfeeding to mothers. The purpose of this study was to analyze the effect of breastfeeding mothers with the incidence of postpartum depression on postpartum mothers. The research method was carried out by a literature review study approach using several journal sources that were selected based on predetermined criteria. The data source is based on updated journals with limited journal publication from 2015-2021. The results were showed the differences in the level of depression in postpartum mothers are due to differences in responses or coping mechanisms possessed by each mother. The conclusion is the risks of postpartum depression were occured due to three factors, which are problems with breastfeeding, husband's support, and income.
\end{abstract}

Keywords: postpartum; breastfeeding mother; postpartum depression

\begin{abstract}
ABSTRAK
Depresi postpartum adalah keadaan depresi yang dialami oleh seorang ibu pasca melahirkan. Depresi postpartum mempengaruhi penurunan maupun penghentian proses pemberian air susu ibu (ASI) pada ibu menyusui. Tujuan dari penelitain ini adalah untuk menganalisis pengaruh ibu menyusui dengan kejadian depresi post partum pada ibu pasca melahirkan. Metode pada penelitian ini yaitu menggunakan pendekatan studi literature review dengan menggunakan beberapa sumber jurnal yang dipilih berdasarkan kriteria yang telah ditetapkan. Sumber datanya berdasarkan jurnal terupdate yang dibatasi penerbitan jurnalnya dari tahun 2015-2021. Hasil literatur dari penelitian perbedaan tingkat depresi pada ibu nifas disebabkan karena perbedaan respon atau mekanisme koping yang dimiliki oleh masing masing ibu. Kesimpulannya adalah risiko terjadi depresi postpartum disebabkan oleh tiga faktor yaitu masalah menyusui, dukungan suami, dan penghasilan.
\end{abstract}

Kata kunci: postpartum; ibu menyusui; depresi postpartum

\section{PENDAHULUAN}

\section{Latar Belakang}

Angka insiden depresi postpartum adalah 1 sampai 2 per 1000 kelahiran sekitar 50 sampai $60 \%$ perempuan yang mengalami depresi postpartum saat mereka memiliki anak pertama, dan sekitar $50 \%$ perempuan yang mengalami postpartum itu mempunyai riwayat keluarga ${ }^{(1)}$. Angka prevalensi depresi postpartumsecara global antara10-15\%(2). angka kejadian depresi postpartum di asia cukup tinggi dan bervariasi antara 26-85\%, sedangkan di indonesia angka kejadian yang terjadi depresi postpartum antara $50-70 \%$ dari wanita pasca persalinan ${ }^{(3)}$.

Depresi pasca persalinan merupakan suatu gangguan emosional ibu berupa adanya perubahan mood yang cepat berubah dan berganti-ganti (Mood Swing), dari tingkatan yang sangat ringan yang bersifat sementara (Baby Blues) sampai depresi psikosa yang sangat berat dan memerlukan penanganan psikiatri. Sekitar 50$80 \%$ ibu bersalin mengalami baby blues dalam sepuluh hari pasca melahirkan. Jika tidak mendapat bantuan ibu yang nengalami baby blues dapat meningkat menjadi depresi yang lebih berat (4).

Faktor penyebab depresi postpartum ada beberapa diantaranya adalah riwayat depresi sebelumnya, dukungan sosial, faktor ekonomi, hubungan pernikahan, faktor obstetri seperti sectio cesaria, persalinan dengan alat. Penelitian di argentina menunjukan multiparitas, komplikasi perinatal, persalinan sesar, dan lama menyusui menjadi faktor risiko gejala depresi postpartum. Masalah menyusui juga disebutkan sebagai salah satu faktor risiko dari depresi postpartum, studi tentang nyeri puting susu terhadap aspek psikologi pada ibu menyusui menunjukkan bahwa 
nyeri puting itu memengaruhi terjadinya depresi pada ibu nifas.

Ada beberapa penyebab utama terjadinya depresi postpartum adalah seperti yang terjadi adanya ketidakseimbangan hormon yaitu hormon estrogen, progesteron, prolactin dan estriol yang fluktuatif setelah melahirkan sehingga hal ini yang berpengaruh terhadap suasana hati diantaranya adalah kecemasan. Kecemasan jika tidak segera ditangani akan bisa berkembang menjadi depresi postpartum dan memberikan efek yang lebih buruk baik terhadap ibu maupun bayi. Studi ini adalah kajian Pustaka (literatur review) bertujuan menganalisis pengaruh ibu menyusui dengan kejadian depresi postpartum pada ibu pasca melahirkan. Berdasarkan hasil penelusuran Pustaka yang terbit pada jurnal yang terindeks. Rumusan masalah adalah faktor apa sajakah yang mempengarungi pada postpartum depression.

\section{METODE PENELITIAN}

Dalam penelitian ini dilakukan pencarian literatur review yaitu artikel ilmiah dengan cara membaca, meringkas, membandingkan dan melakukan kritik serta memberikan pendapat. Melalui media, medline, sage journals, biomed central, dan link springer dan who regional databases. Kata kunci yang dipakai untuk penelusuran literatur yaitu "breastfeeding selfefficacy postpartum depression". Cara yang digunakan dalam mencari artikel menggunakan bahasa inggris dan indonesia yang relevan dengan topik pencarian dilakukan dengan menggunakan beberapa database antara lain pubmed. Pada kolom pencarian setelah muncul 12 judul artikel kemudian peneliti mengamati satu per satu judul sambal memperhatikan abstrak, ditemukan sbagian besar tidak relevan dengan tujuan yang dicari. Setelah diseleksi terdapat 6 artikel yang sesuai kemudian diseleksi lagi berdasarkan metode dan hasil hanya 4 artikel yang layak.

Sedangkan data di pencarian menggunakan google Scholar dengan Keyword yang digunakan adalah "depresi pasca persalinan dan efikasi diri menyusui". Pada kolom pencarian kemudian muncul 119 judul sbagian besar tidaak relevan dengan tujuan. Setelah diseleksi terdapat 12 artikel yang sesuai kemudian diseleksi lagi berdasarkan metode dan hasil hanya 6 artikel yang layak. Sehingga jumlah artikel yang direview sebanyak 10 artikel seperti bagan di bawah.

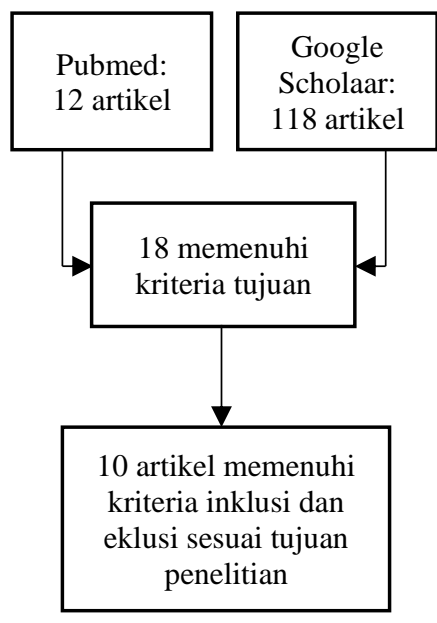

Gambar 1. Bagan detail jumlah pemilihan artikel

Sebagaimana bahwa kriteria artikel dan jurnal yang masuk dalam studi ini yaitu dengan kriteria inklusi: 1) terbit di jurnal terindeks sinta, google schoolar, Pubmed; 2) artikel terbit pada tahun 2015-2021; 3) desain penelitian kuantitatif dan kualitatif; 4) lokasi penelitian dari berbagai daerah di Indonesia dan juga luar negeri. Sehingga jumlah artikel yang diperoleh direview untuk memilih artikel yang sesuai dengan kriteria dan didapatkan 10 artikel yang terdiri dari 4 artikel internasional dan 6 artikel nasional yang selanjutnya akan direview.

Data yang diperoleh dikompilasi dengan cara meringkas, dianalis menggunakan narasi dan disimpulkan sehingga menjadi kesimpulan dari seluruh artikel yang dikaji. Analisa data dilakukan dengan melakukan kajian terhadap seluruh artikel dalam dua tahap yaitu meringkas dan memberikan kritik atau pendapat. Tahap pertama yaitu meringkas artikel (summary). Pada tahap ini peneliti meringkas isi dari sepuluh artikel tersebut meliputi judul artikel/nama penulis, jurnal/tahun terbit/indeks, rancangan penelitian, tujuan dan hasil. Kemudian pembahasan dilanjutkan dengan membandingkan hasil temuan tentang depresi pasca persalinan dan efikasi diri menyusui dengan hasil penelitian orang lain.

\section{HASIL DAN PEMBAHASAN}

Artikel review ini menjelaskan bahwa dari 10 artikel yang direview, 6 diantaranya terbit pada jurnal nasional terindeks jurnal bidan cerdas, stikes sari mulya, jurnal medika udayana, jurnal ilmiah kebidanan (scientific journal of midwifery), jurnal kes mas, jurnal jurnal 
kesehatan "wiraraja medika", pengabdian masyarakat multidisiplin. Dan 4 lainnya dari jurnal internasional elsevier sexual and reproduktif, journal de pediatria, jurnal bmc reseach notes. Berdasarkan tahun terbit, artikel yang terbit pada tahun 2013 ada 3 jurnal, dan 2015 ada 1 dan tahun 2019 masing-masing 2 artikel, pada tahun 2020 dan 2021 masing-masing 2 artikel dan 1 artikel terbit pada tahun 2021.

\section{Tabel 1. Hasil literatur review}

\begin{tabular}{|c|c|c|c|}
\hline Penulis/Judul & $\begin{array}{l}\text { Jurnal (vol, no, } \\
\text { tahun) }\end{array}$ & $\begin{array}{l}\text { Rancangan } \\
\text { penelitian }\end{array}$ & Hasil \\
\hline $\begin{array}{l}\text { Febi Sukma dan Revinel R. } \\
\text { (2020) dengan judul Masalah } \\
\text { Menyusui Sebagai } \\
\text { Determinan Terjadinya Risiko } \\
\text { Depresi Postpartum Pada Ibu } \\
\text { Nifas Normal }\end{array}$ & $\begin{array}{l}\text { Jurnal Bidan } \\
\text { Cerdas Vol. } 2 \text { No. } \\
\text { 3: Agustus } 2020 .\end{array}$ & $\begin{array}{l}\text { Desain kuantitatif } \\
\text { dengan desain } \\
\text { penelitian cross } \\
\text { sectionalpopulasi. } \\
\text { Sampel yang diambil } \\
\text { sebesar } 121 \text { ibu nifas. }\end{array}$ & $\begin{array}{l}\text { Dari penelitian ini adalah hasil } \\
\text { analisis menunjukkan koefisien } \\
\text { positif sebesar } 3,7 \text { dengan nilai or } \\
\text { sebesar } 39,2 \text { artinya ibu yang } \\
\text { memiliki masalah menyusui dapat } \\
\text { risiko terjadi depresi postpartum } \\
\text { sebesar } 39,2 \text { kali lebih besar } \\
\text { daripada ibu yang tidak memiliki } \\
\text { masalah menyusui. }\end{array}$ \\
\hline $\begin{array}{l}\text { Lisa Fitriani, Dini } \\
\text { Rahmayani, Rina Alkahfi } \\
\text { (2018), dengan judul } \\
\text { Hubungan Ibu Menyusui } \\
\text { Dengan Kejadian Depresi } \\
\text { Post Partum Di Rumah Sakit } \\
\text { Umum Sari Mulia } \\
\text { Banajrmasin }\end{array}$ & $\begin{array}{l}\text { Jurnal Stikes Sari } \\
\text { Mulya. }\end{array}$ & $\begin{array}{l}\text { Penelitian kuantitatif } \\
\text { dengan pendekatan } \\
\text { cross sectional, } \\
\text { dengan instrument } \\
\text { epds (edinburgh } \\
\text { postnatal depression } \\
\text { scale) }\end{array}$ & $\begin{array}{l}\text { Hasil penelitian didapatkan } \\
\text { bahwa ibu menyusui sebanyak } 32 \\
(91,4 \%) \text { orang, ibu yang } \\
\text { mengalami depresi postpartum } \\
\text { sebanyak } 5(14,3 \%) \text { orang. }\end{array}$ \\
\hline $\begin{array}{l}\text { Kadek Rudita Yasa dan } \\
\text { Cokorda Bagus Jaya Lesmana } \\
\text { (2019) dengan judul Tingkat } \\
\text { Depresi Postpartum Pada Ibu } \\
\text { Menyusui Di Puskesmas } \\
\text { Denpasar Timur }\end{array}$ & $\begin{array}{l}\text { Jurnal Medika } \\
\text { Udayana, Vol. } 8 \\
\text { No. 12, Desember } \\
2019 .\end{array}$ & $\begin{array}{l}\text { Penelitian deskriptif } \\
\text { observasional } \\
\text { menggunakan } \\
\text { pendekatan cross } \\
\text { sectional. } 53 \text { sampel } \\
\text { ibu menyusui }\end{array}$ & $\begin{array}{l}\text { Hasil tingkat depresi postpartum } \\
\text { ibu menyusui memiliki hubungan } \\
\text { signifikan dengan jumlah } \\
\text { penghasilan }(p=0,010) \text { dan pilihan } \\
\text { persalinan }(p=0,014) \text {. }\end{array}$ \\
\hline $\begin{array}{l}\text { Anik Latifah (2021) dengan } \\
\text { judul Hubungan Depresi } \\
\text { Postpartum Terhadap } \\
\text { Pengeluaran Asi Di Rumah } \\
\text { Sakit Ibu Dan Anak Cempaka } \\
\text { Putih Surabaya }\end{array}$ & $\begin{array}{l}\text { Jurnal Ilmiah } \\
\text { Kebidanan } \\
\text { (Scientific Journal } \\
\text { of Midwifery), } \\
\text { Vol. 7, No. 1 } \\
\text { Tahun 2021. }\end{array}$ & $\begin{array}{l}\text { Penelitian kuantitatif } \\
\text { dengan pendekatan } \\
\text { cross sectional di } \\
\text { mana pengukuran } \\
\text { variabel variabelnya } \\
\text { dilakukan hanya satu } \\
\text { kali. }\end{array}$ & $\begin{array}{l}15 \text { sampel yang diambil } \\
\text { didapatkan hasil } 9 \text { responden } \\
(60 \%) \text { tidak mengalami resiko } \\
\text { depresi, sebagian besar usia } \\
\text { responden } 20-35 \text { tahunsebanyak } \\
12 \text { responden }(80 \%) \text {, sebagian } \\
\text { besar berpendidikan tinggi } \\
\text { sebanyak } 9 \text { responden }(60 \%) \\
\text { sebagian besar sudah keluar asi } \\
\text { dalam waktu } 48 \text { jam sebanyak } 12 \\
\text { responden }(80 \%) .\end{array}$ \\
\hline $\begin{array}{l}\text { Carloz Zubaran dan Foresti } \\
\text { K. (2013) yang berjudul The } \\
\text { Correlation Between } \\
\text { Breastfeeding Self-Efficacy } \\
\text { And Maternal Postpartum } \\
\text { Depression In Southern } \\
\text { Brazil. }\end{array}$ & $\begin{array}{l}\text { Jurnal } \\
\text { Internasional } \\
\text { Elsevier Sexual } \\
\text { and Reproductive } \\
\text { Healthcare Vol. 4, } \\
\text { No. 1. 9-15. }\end{array}$ & $\begin{array}{l}\text { Studi cross-sectional. } \\
\text { Dengan hasil } \\
\text { sebanyak } 89 \mathrm{ibu} \\
\text { menyelesaikan } \\
\text { investigasi }\end{array}$ & $\begin{array}{l}\text { Ibu yang menggabungkan asi dan } \\
\text { susu botol menunjukkan skor pdss } \\
\text { dan epds yang lebih tinggi. Skor } \\
\text { self-efficacy menyusui lebih tinggi } \\
\text { pada ibu yang memberikan asi } \\
\text { eksklusif dan dikaitkan secara } \\
\text { negatif (p <0,001) dengan skor } \\
\text { epds dan pdss (depresi } \\
\text { postpartum). }\end{array}$ \\
\hline $\begin{array}{l}\text { Erika de Sa Vieira, Dkk. } \\
\text { (2018) dengan judul } \\
\text { Breastfeeding Self-Efficacy } \\
\text { And Postpartum Depression: } \\
\text { A Cohort Study. }\end{array}$ & $\begin{array}{l}\text { Journal de } \\
\text { Pediatria Vol. } 89 \\
\text { Issued } 4 \text { Juli- } \\
\text { Agustus 2013. }\end{array}$ & $\begin{array}{l}\text { Studi kohort } \\
\text { prospektif yang } \\
\text { dilakukan di incentive } \\
\text { and support center for } \\
\text { breastfeeding and } \\
\text { human milk bank. }\end{array}$ & $\begin{array}{l}\text { Menyusui dapat berperan sebagai } \\
\text { faktor pelindung depresi selama } \\
\text { nifas, meningkatkan kesejahteraan } \\
\text { psikologis ibu (yaitu melalui } \\
\text { pengaturan pola tidur dan terjaga. }\end{array}$ \\
\hline
\end{tabular}




\section{Vol. 16 No. 3 September - Desember 2021}

\begin{tabular}{|c|c|c|c|}
\hline $\begin{array}{l}\text { Payam Amini., Dkk. (2019) } \\
\text { dengan judul the } \\
\text { Breastfeeding Self-Efficacy } \\
\text { Scale-Short Form (Bses-Sf): } \\
\text { A Validation Study In Iranian } \\
\text { Mothers. }\end{array}$ & $\begin{array}{l}\text { Jurnal bmc } \\
\text { research notes }\end{array}$ & Studi cross-sectional & $\begin{array}{l}\text { Dengan hasil usia ibu rata-rata ibu } \\
\text { adalah } 30,13 \text { tahun (sd = 5,81; } \\
\text { kisaran 16-45). Dari peserta, } \\
29,8 \% \text { berpendidikan universitas, } \\
12,9 \% \text { bekerja, } 57,6 \% \text { primipara. } \\
\text { Cs dilaporkan sebanyak 72,7\% } \\
\text { dari sampel (65,3\% di antaranya } \\
\text { menanggapi cs yang } \\
\text { direncanakan. }\end{array}$ \\
\hline $\begin{array}{l}\text { Lina Handayani, Dkk. (2013) } \\
\text { dengan judul Translation And } \\
\text { Validation Of Breastfeeding } \\
\text { Self-Efficacy Scale Short } \\
\text { Form (BSES-SF) Into } \\
\text { Indonesian: A Pilot Study. }\end{array}$ & $\begin{array}{l}\text { Jurnal Kesehatan } \\
\text { Masyarakat Vol. } 7 \\
\text { No. 1, Maret } 2013\end{array}$ & $\begin{array}{l}\text { Diuji menggunakan } \\
\text { analisis dengan } \\
\text { korelasi pearson }(r) \\
\text { dengan titik potong } \\
\text { adalah } 0,5 \text {. Dari segi } \\
\text { nilai } r \text { lebih dari } 0,5 \text {, } \\
\text { artinya item tersebut } \\
\text { valid }\end{array}$ & $\begin{array}{l}\text { Instrumen yang cocok untuk } \\
\text { menilai kepercayaan diri ibu } \\
\text { dalam menyusui di antara ibu-ibu } \\
\text { indonesia }\end{array}$ \\
\hline $\begin{array}{l}\text { Ratna Indriyani (2015) } \\
\text { dengan judul Hubungan } \\
\text { Postpartum Blues, Dan } \\
\text { Efikasi Diri Dengan } \\
\text { Pelaksanaan Senam Nifas Di } \\
\text { Polindes Tunas Bunda Desa } \\
\text { Manddelen Kecamatan } \\
\text { Lenteng Tahun 2015. }\end{array}$ & $\begin{array}{l}\text { Jurnal Kesehatan } \\
\text { "Wiraraja } \\
\text { Medika" }\end{array}$ & $\begin{array}{l}\text { Metode penelitian } \\
\text { observasional analitik } \\
\text { adapun rancang } \\
\text { bangun yang } \\
\text { digunakan dalam } \\
\text { penelitian ini adalah } \\
\text { cross sectional }\end{array}$ & $\begin{array}{l}\text { Hasil hasil penelitian yang paling } \\
\text { mungkin mengalami postpartum } \\
\text { blues }(54,8 \%) \text {, sebagian besar } \\
\text { mengalami a efikasi diri positif } \\
(58,1 \%) \text {, dan sebagian besar } \\
\text { pelaksanaan senam nifas adalah } \\
\text { negatif }(61,3 \%) \text {. }\end{array}$ \\
\hline $\begin{array}{l}\text { Lailiyana dan Elli Susilawati } \\
\text { (2020) dengan judul } \\
\text { Sosialisasi Dan Penerapan } \\
\text { Edinburgh Postnatal } \\
\text { Depression Scale (EPDS) } \\
\text { Oleh Bidan Dalam Upaya } \\
\text { Deteksi Dini Depresi Pada } \\
\text { Ibu Postpartum Di Puskesmas } \\
\text { Kota Pekanbaru. }\end{array}$ & $\begin{array}{l}\text { Jurnal Pengabdian } \\
\text { Masyarakat } \\
\text { Multidisiplin } \\
\text { Volume 4, No. 1| } \\
\text { Oktober 2020, } \\
\text { Hal: 55-60 }\end{array}$ & $\begin{array}{l}\text { Metode kegiatan } \\
\text { pengabdian } \\
\text { masyarakat ini } \\
\text { dilakukan dengan cara } \\
\text { melakukan sosialisasi } \\
\text { epds }\end{array}$ & $\begin{array}{l}\text { Hasil } \\
\text { monitoring } \\
\text { dan evaluasi } \\
\text { didapatkan } \\
\text { peningkatan } \\
\text { penerapan } \\
\text { epds oleh } \\
\text { bidan untuk } \\
\text { deteksi dini } \\
\text { masalah } \\
\text { psikologis ibu } \\
\text { postpartum } \\
\text { yaitu dari } \\
66,7 \text { menjadi } \\
88,9 .\end{array}$ \\
\hline
\end{tabular}

Dari hasil literatur riview yang telah dipaparkan di dapatkan perbedaan tingkat depresi pada ibu nifas disebabkan karena perbedaan respon atau mekanisme koping yang dimiliki oleh masing masing ibu. Pada ibu setelah melahirkan banyak faktor yang menjadi pemicu terjadinya depresi, adanya perasaan tidak nyaman, kelelahan, ketidak tahuan tentang merawat bayi, adanya dukungan keluarga, harapan terhadap kelahiran bayi, temperamen ibu, karakteristik bayi, kondisi yang tidak terduga berkaitan dengan proses persalinan. Depresi postpartum biasanya juga disebut sebagai postpartum blues yang mana merupakan suatu sindrom gangguan efek yang ringan sering tampak dalam minggu pertama setelah persalinan cenderung akan memburuk pada hari ketiga sampai kelima dalam rentangwaktu 14 hari atau dua minggu postpartum. Depresi postpartum dapat menganggu keharmonisan pasangan suami istri serta menimbulkan perasaan yang tidak nyaman bagi ibu yang mengalaminya ${ }^{(15)}$.

Periode ini yang terdapat di postpartum merupakan situasi krisis bagi ibu, pasangan, dan keluarga akibat berbagai perubahan yang terjadi baik secara fisik, psikologis, maupun struktur 
keluarga yang memerlukan proses adaptasi atau penyesuaian. Keadaan di mana seorang ibu mengalami perasaan tidak nyaman setelah persalinan, yang berkaitan dengan hubungannya dengan si bayi, atau pun dengan dirinya sendiri. Ketika plasenta dikeluarkan pada saat persalinan, terjadi perubahan hormon yang melibatkan pada endorphin, progesteron, dan estrogen yang di dalam tubuh ibu tersebut, yang pasti dapat mempengaruhi kondisi fisik, mental dan emosional ibu. Adaptasi secara fisik dimulai sejak bayi dilahirkan sampai kembalinya kondisi tubuh ibu pada kondisi seperti sebelum hamil, yaitu kurun waktu 6 sampai 8 minggu. Proses adaptasi psikologi pada seorang ibu sudah di mulai sejak dia hamil. Kehamilan dan persalinan merupakan peristiwa yang normal terjadi dalam hidup, namun banyak ibu yang mengalami stres yang signifikan $^{(16)}$. Berdasarkan hasil penelitian terlihat bahwa ibu menyusui yang mengalami depresi postpartum paling banyak adalah pada usia 20-35 tahun.

\section{KESIMPULAN DAN SARAN}

\section{Kesimpulan}

Temuan ini menunjukkan bahwa ibu yang menderita gejala depresi mungkin mengalami kurang percaya diri pada kemampuannya untuk menyusui. Asosiasi ini mungkin relevan secara khusus untuk tujuan prosedur skrining untuk depresi dan menyusui yang tidak memuaskan selama periode postpartum.

Risiko terjadi depresi postpartum disebabkan oleh tiga faktor yaitu masalah menyusui, dukungan suami, dan penghasilan, dengan masalah menyusui sebagai faktor paling dominan dari ketiga faktor tersebut.

Secara keseluruhan tingkat menyusui asi eksklusif berbeda-beda disetiap negara dan wilayah. Banyak faktor yang mempengaruhi terjadinya depresi yaitu seperti suatu adanya kurangnya dukungan dari pasangan atau dengan keluarga terdekat, usia, pendapatan rendah, riwayat depresi, pendidikan dan lain sebagainnya. Ibu postpartum dengan gejala pada depresi itu dapat mempengaruhi keberhasilan pada asi eksklusif yang dikarenakan ada perubahan hormon dan mood (perasaan) yang terjadi pada ibu seperti ibu tidak nafsu makan, gangguan tidur, cemas, sensitif sehingga bisa dapat mengganggu kelancaran asi.

\section{Saran}

1. Diharapkan bagi tenaga kesehatan dapat melakukan skrening dini pada saat ibu melakukan anc dan menindaklanjuti bagi ibu nifas yang memiliki gejala depresi postpartum agar tidak meningkat menjadi depresi postpartum.

2. Dari penelitian ini diharapkan menjadi masukan bagi ibu nifas, dan pasangan untuk mempersiapkan diri dalam menghadapi masa nifas, diantaranya peningkatan pendidikan kesehatan laktasi untukmengurangi masalah yang mungkin terjadi dalam menyusui. Dukungan suami dapat ditumbuhkan sejak masa kehamilan dengan ikut serta dalam pemeriksaan kehamilan dan mengikuti kelas hamil. Tenaga kesehatan sangat berperan penting dalam pencegahan dan deteksi dini risiko depresi postpartum.

\section{DAFTAR PUSTAKA}

1. Williamson, Karney B. R. and. (2017). marital satisfaction and marital problems over time. 4(56), 869-883. 10.1111/famp. 12264.

2. Mohammadi, N. et al. (2016). Iranian pregnant teenage women tell the story of "fast development": A phenomenological study', Women and Birth. Australian College of Midwives. 4(29), 303-309.

3. Da, D. al. (2019). breastfeeding experiences and perspectives among women with postnatal depression. A Qualitative Evidence Synthesis, 1-9.

4. Andri, P. (2010). Not a little monster!memahami, mengasuh dan mendidik anak hiperakti. media komputindo.

5. Sukma, F., \& Revinel, R. (2020). Masalah Menyusui sebagai Determinan Terjadinya Risiko Depresi Postpartum pada Ibu Nifas Normal. Jurnal Bidan Cerdas, 2(3), 121131. https://doi.org/10.33860/jbc.v2i3.69

6. Fitriani L., Dkk. (2018) Hubungan Ibu Menyusui Dengan Kejadian Depresi Post Partum Di Rumah Sakit Umum Sari Mulia Banajrmasin. STIKES Sari Mulia [Internet]. Available from: http://repository.unism.ac.id/173/2/NASK AH\%20LISA.pdf

7. Kadek Rudita Yasa, C. B. J. Lesmana. (2019). Tingkat Depresi Postpartum Pada Ibu Menyusui Di Puskesmas Denpasar Timur I. Jurnka Medika Udayana, 8(12). 


\section{Vol. 16 No. 3 September - Desember 2021}

8. Latifah A. Hubungan Depresi Post Partum Terhadap Pengeluaran Asi Di Rumah Sakit Ibu Dan Anak Cempaka Putih Surabaya. Jurnal Ilmiah Kebidanan (Scientific Journal of Midwifery). 2021;7(1):26-30.9. Zubaran, C., \& Foresti, K. (2013). The correlation between breastfeeding self-efficacy and maternal postpartum depression in southern Brazil. Sexual and Reproductive Healthcare, 4(1), 9-15. https://doi.org/10.1016/j.srhc.2012.12.001

10. Vieira, E. de S., Caldeira, N. T., Eugênio, D. S., Di Lucca, M. M., \& Silva, I. A. (2018). Breastfeeding self-efficacy and postpartum depression: A cohort study. Revista Latino-Americana de Enfermagem, 26. https://doi.org/10.1590/15188345.2110.3035

11. Amini, P., Omani-Samani, R., Sepidarkish, M., Almasi-Hashiani, A., Hosseini, M., \& Maroufizadeh, S. (2019). The Breastfeeding Self-Efficacy ScaleShort Form (BSES-SF): A validation study in Iranian mothers. BMC Research Notes, 12(1), 1-6. https://doi.org/10.1186/s13104-019-46567

12. Handayani, L., Kosnin, A. M., Jiar, Y. K., \& Solikhah, . (2013). Translation and Validation of Breastfeeding Self-Efficacy Scale-Short Form (BSES-SF) into Indonesian: a Pilot Study. Jurnal Kesehatan Masyarakat (Journal of Public Health), 7(1), 21-26. https://doi.org/10.12928/kesmas.v7i1.102 3.

13. Indriyani, R. (2015). Hubungan Postpartum Blues, Dan Efikasi Diri Dengan Pelaksanaan Senam Nifas Di Polindes Tunas Bunda Desa Manddelen Kecamatan Lenteng Tahun 2015. Jurnal Kesehatan "Wiraraja Medika," 21-35.

14. Lailiyana, \& Susilawati, E. (2020). Sosialisasi dan penerapan. Jurnal Pengabdian Masyarakat Multidisiplin, 4(1), 55-60.

15. Susanti. (2018). Buku Ajar Patologi Obstetri Untuk Mahasiswa Kebidanan. egc.

16. John, N. A. et al. (2017). HHS Public Access. 2(19), 267-278. 